\title{
Limitations of clonality analysis of B cell proliferations using CDR3 polymerase chain reaction
}

M A Hoeve, A D G Krol, K Philippo, P W B Derksen, R A Veenendaal, E Schuuring, Ph M Kluin, J H J M van Krieken

\begin{abstract}
BackgroundlAims-Detection of clonal immunoglobulin heavy chain (IgH) rearrangements by the polymerase chain reaction (PCR) is an attractive alternative to Southern blotting in lymphoma diagnostics. However, the advantages and limitations of PCR in clonality analysis are still not fully appreciated. In this study, clonality was analysed by means of PCR, focusing in particular on the sample size requirements when studying extremely small samples of polyclonal and monoclonal lesions.
\end{abstract}

Materials/Methods-High resolution complementarity determining region 3 (CDR3) PCR was used to investigate the minimum number of cells and the amount of tissue required for the detection of a polyclonal population, both for fresh cells and formalin fixed, paraffin wax embedded tissue. Subsequently, frozen and paraffin wax embedded samples of $76 \mathrm{~B}$ cell lymphoproliferative disorders, 43 of which were tested by means of Southern blotting, were analysed to establish the sensitivity of this assay. These specimens included 12 chronic lymphocytic leukaemias (CLLs), nine mantle cell lymphomas (MCLs), 10 follicular lymphomas (FLs), and 45 mucosa associated lymphoid tissue (MALT) lymphomas. The specificity was tested on reactive lymph nodes $(n=19)$, tonsils $(\mathrm{n}=4)$, peripheral blood lymphocyte fractions $(n=4)$, and biopsies with gastritis $(\mathrm{n}=21)$.

Results-In reactive tissue, $20 \mathrm{ng}$ of high molecular weight DNA derived from 6.5$9 \times 10^{3}$ B cells was sufficient to obtain a polyclonal PCR result. With smaller amounts "pseudoclonality" could be induced. When using paraffin wax blocks, undiluted DNA isolated from tonsillar tissue of at least $1 \mathrm{~mm}^{2}$ was necessary to obtain a polyclonal pattern. The sensitivity required to detect clonality in paraffin wax embedded and frozen tissue by PCR for FL ( $40 \%$ and $60 \%$, respectively) was lower than that for MALT lymphomas (60\% and $86 \%$, respectively), CLL $(78 \%$ and $89 \%$, respectively), and MCL (88\% and $100 \%$, respectively). PCR specificity was $96 \%$ and $100 \%$ for frozen and paraffin wax embedded tissue, respectively. Conclusion-The minimum amount of template for CDR3 PCR is approximately
$20 \mathrm{ng}$ of high molecular weight DNA or $1 \mathrm{~mm}^{3}$ of $B$ cell rich paraffin wax embedded normal tonsillar tissue, but care has to be taken to avoid pseudoclonality when low numbers of $B$ cells are present. Duplicate or triplicate tests should be performed to avoid misinterpretation. The specificity of the PCR assay is almost $100 \%$, whereas sensitivity depends on a combination of factors, such as lymphoma type and tissue fixation. Because frozen samples yield better results, obtaining fresh material for the PCR assay is recommended, especially when analysing FL and MALT lymphomas. (F Clin Pathol: Mol Pathol 2000;53:194-200)

Keywords: B cell clonality analysis; complementarity determining region 3; polymerase chain reaction; immunoglobulin gene rearrangement; non-Hodgkin's lymphoma

The distinction between neoplastic and reactive disorders in the diagnosis of nonHodgkin's lymphomas still presents a challenge to the pathologist. In some cases, morphological and immunophenotypic features can be difficult to interpret. Demonstrating clonality by the detection of clonal immunoglobulin (Ig) or T cell receptor (TCR) rearrangements provides a strong argument for neoplasia in this situation. Established methods for detection are immunohistochemistry for Ig light chain restriction and Southern blot analysis. However, these methods are not suitable in all cases, especially when handling small biopsies, fine needle aspirates, tissues with a minor lymphomatous component, or formalin fixed, paraffin wax embedded tissues. ${ }^{1}$

Clonality analysis of lymphoid cells using the polymerase chain reaction (PCR) to amplify the VDJ junctional region of the immunoglobulin heavy chain (IgH) gene ${ }^{23}$ can circumvent some of the disadvantages of the other techniques, and seems to be a useful diagnostic aid. ${ }^{4-11}$ It can be applied to small samples, such as endoscopic biopsies and microdissected tissue. ${ }^{12-14}$ However, neither the limitations of PCR with respect to tumour sample size and numbers of tumour cells, nor the success rate in paraffin wax embedded and frozen tissue of different lymphoma types are well established. Moreover, the sensitivity of the assay allows the detection of small imbalances in B cell populations, raising the possibility of false positive results. 
In our study, we describe a high resolution complementarity determining region 3 (CDR3) PCR protocol, using primers directed at the conserved framework 3 (FR3) area of the $\mathrm{VH}$ gene and the $3^{\prime}$ end of the JH gene. First, the minimum number of cells and size of tissue sample required for the detection of a polyclonal population (as defined by a normal distribution of PCR products) was investigated in both fresh cells and formalin fixed, paraffin wax embedded tissues. We then analysed a series of different lymphoproliferative disorders to establish the predictive value of this PCR protocol. To focus on potential problems caused by mutations in the PCR target area, we selected cases of follicular lymphoma (FL) and mucosa associated lymphoid tissue (MALT) lymphoma and compared them with chronic lymphocytic leukaemia (CLL) and mantle cell lymphoma (MCL) (both known to have a more stable genetic structure). To investigate the effect of routine fixation in formalin, in 43 of the 76 tumours, we performed PCR on both frozen and formalin fixed, paraffin wax embedded samples and compared the results. The specificity of the method was evaluated by analysing reactive lymph nodes, tonsils, peripheral blood lymphocytes, and biopsies with gastritis.

\section{Materials and methods}

TISSUES

Frozen tissue samples and phosphate buffered saline (PBS) buffered, formalin fixed, paraffin wax embedded tissues from 76 non-Hodgkin's lymphomas were retrieved from the lymphoma bank of the department of pathology, Leiden University Medical Centre. These tumours had been classified previously by morphological and immunophenotypic criteria. For the purpose of our study all slides were reviewed. Southern blot analysis for Ig gene rearrangement had been performed on 43 of the 76 cases and revealed a detectable $\mathrm{JH}$ rearrangement in all of these.

To establish the influence of lymphoma type on PCR sensitivity, we selected 12 cases of CLL, nine MCLs, 45 MALT lymphomas, and 10 FLs. Non-malignant lymph nodes $(n=19)$, tonsillectomy specimens from otherwise healthy children $(n=4)$, biopsies with gastritis $(\mathrm{n}=21)$, and peripheral blood lymphocytes from healthy donors ( $n=4)$ were used as controls. A clone containing lymphoma sample and a mixture of three Epstein-Barr virus (EBV) transformed cell lines served as monoclonal and oligoclonal controls, respectively.

DNA PREPARATION

DNA from frozen tissue samples was obtained using proteinase $\mathrm{K}$ digestion and standard phenol/chloroform extraction. DNA from formalin fixed, paraffin wax embedded tissues was purified by dissolving three to five $5 \mu \mathrm{m}$ sections in $97 \mu \mathrm{l}$ buffer containing $10 \mathrm{mM}$ Tris/ $\mathrm{HCl}(\mathrm{pH} 8.3), 1 \mathrm{mM}$ EDTA, $0.5 \%$ Tween 20 , and $3 \mu \mathrm{l}$ proteinase $\mathrm{K}(10 \mathrm{mg} / \mathrm{ml})$ at $56^{\circ} \mathrm{C}$ overnight. After boiling for five minutes, samples were spun down and the recovered supernatants were used as the template for PCR. PCR performed on undiluted superna- tants containing DNA from paraffin wax embedded tissues often resulted in nonspecific or negative test results. Because this was probably the result of variations in the DNA content of supernatants and/or factors present in the fixative or paraffin wax interfering with PCR amplification, we made serial dilutions of these supernatants (undiluted, $1 / 10,1 / 100$, and 1/1000), which were then used as templates for the PCR. The presence of the tumour cells was evaluated in each tissue block on haematoxylin and eosin stained slides that were cut before and after the sections used for DNA isolation.

PCR AMPLIFICATION

PCR amplification of rearrangements at the IgH locus was performed using the consensus primers FR3A, with a reported homology of at least $85 \%$ with $95 \%$ of the published $\mathrm{VH}$ gene sequence $^{6}$ (5'-ACA CGG CC/T G/C TGT ATT ACT GT-3'), and LJH (5'-CCT GAG GAG ACG GTG ACC-3'), which anneal to variable and joining gene segments, respectively. ${ }^{315}$ The PCR reaction mixture (30 $\mu \mathrm{l})$ contained $200 \mathrm{ng}$ DNA from frozen samples, or $5 \mu \mathrm{l}$ sample extracted from paraffin wax embedded tissue, in $10 \mathrm{mM}$ Tris $/ \mathrm{HCl}$ (pH 8.4), $50 \mathrm{mM} \mathrm{KCl}, 1.5 \mathrm{mM} \mathrm{MgCl}_{2}, 2 \mathrm{mg} /$ $\mathrm{ml}$ bovine serum albumin (BSA; Organon Technica, Boxtel, The Netherlands), $500 \mathrm{nM}$ of each primer (Life Technologies, Paisley, UK), $200 \mu \mathrm{M}$ dNTPs, $1.5 \mu \mathrm{Ci}\left[\alpha{ }^{32} \mathrm{P}\right] \mathrm{dCTP}$ (Amersham, Little Chalfont, UK), and $0.3 \mathrm{U}$ Taq DNA polymerase (PE Biosystems, Foster City, California, USA).

PCR reactions were performed in a DNA thermal cycler (PE Biosystems). Amplification was started with a denaturation step of seven minutes at $94^{\circ} \mathrm{C}$, followed by 35 cycles consisting of 40 seconds denaturation at $94^{\circ} \mathrm{C}, 40$ seconds annealing at $55^{\circ} \mathrm{C}$, and 40 seconds extension at $72^{\circ} \mathrm{C}$. After denaturation of $4 \mu \mathrm{l}$ of PCR product for five minutes at $94^{\circ} \mathrm{C}$ in a solution containing $50 \%$ formamide, $0.025 \%$ xylene cyanol, $10 \mathrm{mM}$ EDTA, and $0.025 \%$ bromophenol blue, PCR samples were put on ice for five minutes and analysed on a $6 \%$ denaturing polyacrylamide gel for optimal separation of PCR products. PCR products were visualised by autoradiography. All reactions were performed in duplicate. PCR products of DNA extracted from paraffin wax embedded tissue and frozen tissue from the same tumour were loaded on to the same gel to enable comparison of electrophoresis patterns. As controls, with each PCR, DNA obtained from normal peripheral blood lymphocytes or tonsil, a mix of DNA from three monoclonal EBV transformed cell lines, and DNA from a CLL tumour known to give a strong monoclonal pattern was amplified as a polyclonal, oligoclonal, and monoclonal control, respectively. Water was used as a negative control. For the analysis of DNA purified from frozen material, results were considered conclusive only when duplicate experiments on undiluted DNA showed the same results. For the analysis of DNA obtained from paraffin wax embedded tissue, results were considered conclusive when 
undiluted DNA and one dilution or two or more serial dilutions of template DNA showed the same patterns.

Results

Amplification of DNA extracted from frozen tissues resulted in five different patterns.

(1) Monoclonal (M): one or two strong, dominant band(s) within the expected size

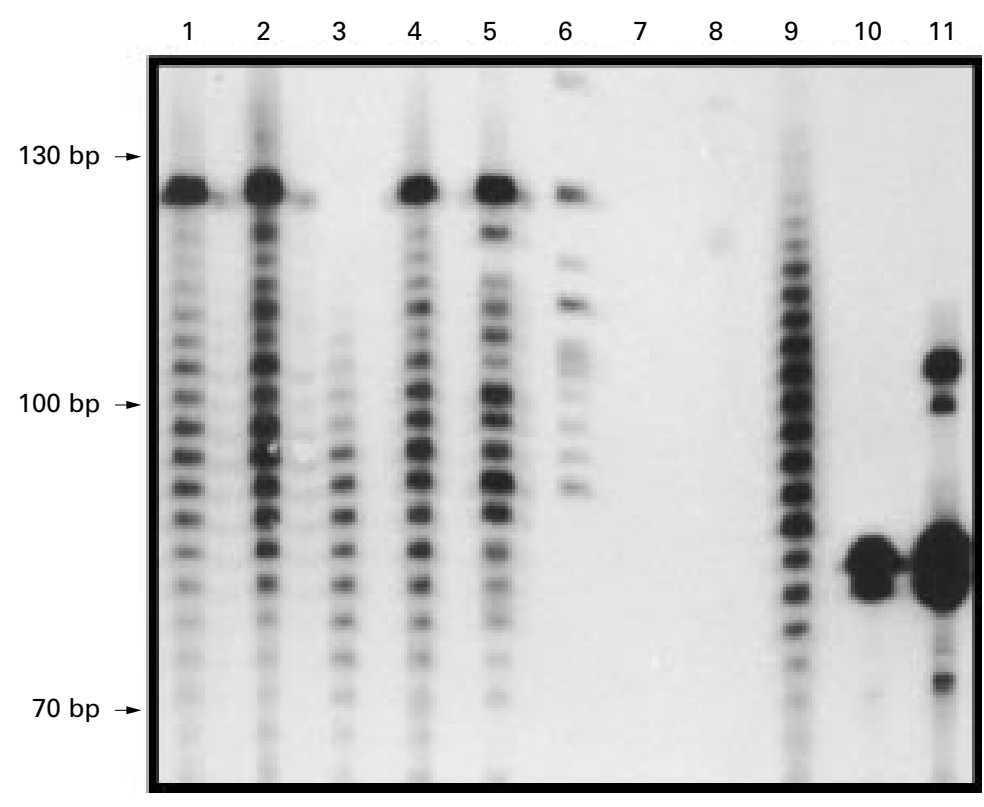

Figure 1 Results of the complementarity determining region 3 (CDR3) polymerase chain reaction. Lanes 1-6, lymphoma case lanes 1 and 2, $200 \mathrm{ng}$ DNA from frozen tissue, showing a clonal band in a polyclonal background; lanes 3-6, DNA from paraffin wax embedded tissue, undiluted and 1/10,1/100 and 1/1000 dilutions, respectively, giving the same clonal band in the three diluted samples); lane 7, water; lane 8, furkatt T cell line; lane 9, peripheral blood lymphocyte fraction, showing a polyclonal ladder of the expected size range; lane 10, positive control (chronic lymphocytic leukaemia (CLL) DNA); lane 11, positive control (CLL DNA mixed with DNA from an Epstein-Barr virus infected cell line).

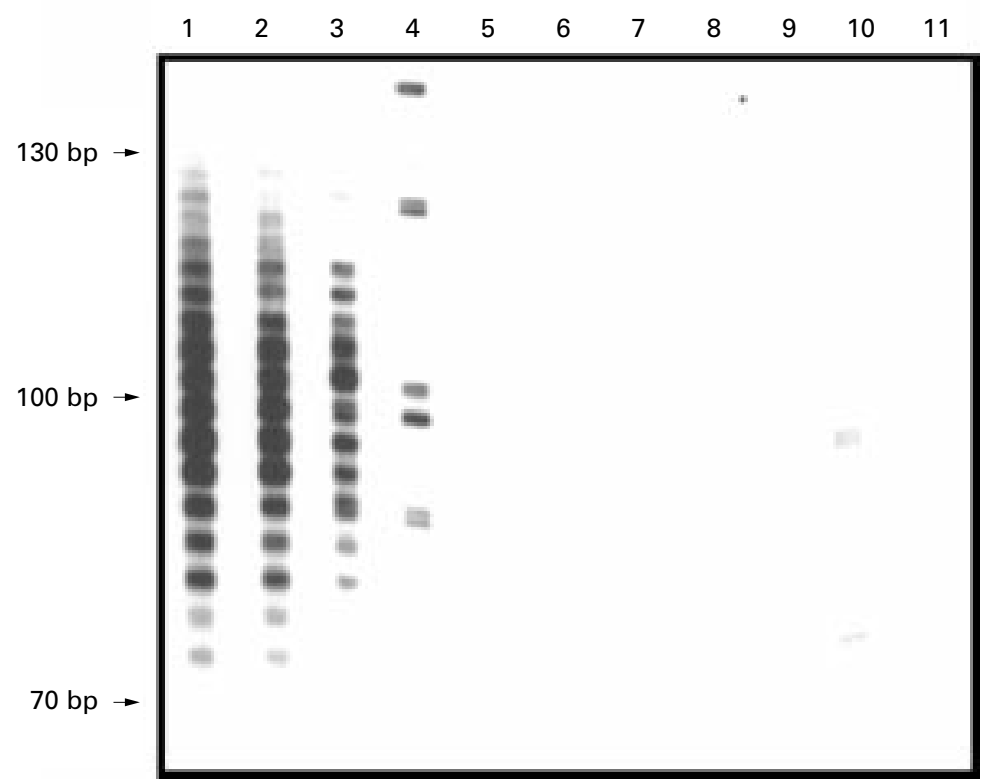

Figure 2 Complementarity determining region 3 (CDR3) polymerase chain reaction on a dilution series of DNA isolated from a frozen sample of a reactive tonsil. Lane 1, $200 \mathrm{ng}$ DNA, showing a normally distributed polyclonal ladder; lanes 2-11, 10 fold dilution steps producing oligoclonal patterns with randomly (dis) appearing bands. range $(70-130 \mathrm{bp})$, either as the sole product (fig 1 ; lane 10), or superimposed on a background of multiple, far weaker bands (fig 1; lanes 1, 2, 4, and 5). In the case of two bands, the products could be derived from biallelic VDJ rearrangement, one being functional.

(2) Oligoclonal (O): three or more bands, reproducible in duplicate experiments, sometimes superimposed on a polyclonal background (fig 1; lane 11).

(3) Polyclonal (P): a ladder of 10-20 bands, with a Gaussian distribution over the expected size range (fig 1; lane 9).

(4) Incomplete polyclonal (IP): less than 10 bands in the expected size range, randomly distributed, of different intensities, and varying between duplicate experiments (fig 1 ; lane 6).

(5) No signal (NS): no products, or only weak bands outside the expected size range (fig 1 ; lanes 7 and 8 ).

\section{AMOUNT OF B CELLS NECESSARY TO DETECT} POLYCLONALITY

By serially diluting 200 ng DNA isolated from frozen tissue of a normal tonsil, and subsequent PCR on all diluted samples, we determined the minimum amount of DNA required for reliable PCR results. Approximately $20 \mathrm{ng}$ of DNA appeared to be sufficient to obtain the expected polyclonal pattern. With smaller amounts of DNA, the numbers of bands diminished because of less efficient amplification of the relatively smaller and larger CDR3 regions, and (non-reproducible) incomplete polyclonal patterns (200 ng DNA diluted $10^{2}-$ $10^{3}$ fold (fig 2 ; lanes 3 and 4 ) or pseudomonoclonal patterns $\left(10^{9}\right.$ fold dilution; fig 2 ; lane 10$)$ were produced. The $20 \mathrm{ng}$ of DNA required for reliable PCR assays is equivalent to $10^{4}$ lymphocytes - the template providing cells.

To establish whether this amount of DNA could be isolated from small biopsies embedded in paraffin wax, we also tested extremely small paraffin wax embedded fragments of a normal tonsil, ranging in size from 1 to $4 \mathrm{~mm}^{2}$, as a source of template for the PCR. Each sample was cut into $5 \mu \mathrm{m}$ sections and one to five sections were collected in Eppendorff tubes. DNA was isolated and CDR3 PCR was performed successfully, both on undiluted and diluted supernatants. Depending on the size and number of sections, incomplete polyclonal patterns were produced starting from the $1 / 10$, $1 / 100$, or $1 / 1000$ dilution of a sample (table 1 ).

In addition to the required minimum amount of DNA, there may also be restrictions to the maximum amount of template used in the PCR. Undiluted material might give weak or even false negative PCR results, possibly as a consequence of inhibitory factors present in the crude extracts from formalin fixed, paraffin wax embedded material (fig 1 ; lane $3 v$ lane 4 ).

COMPARISON OF PCR ON FROZEN AND PARAFFIN WAX EMBEDDED TISSUES

PCR products obtained after amplification of diluted supernatants of template isolated from formalin fixed, paraffin wax embedded tissues 
Table 1 Complementarity determining region 3 (CDR3) polymerase chain reaction results on sections of small, paraffin wax embedded tonsillar tissue

\begin{tabular}{|c|c|c|c|c|c|c|c|c|c|c|c|c|}
\hline & \multicolumn{12}{|c|}{ Tonsil sample size $\left(\mathrm{mm}^{2}\right)$} \\
\hline & \multicolumn{4}{|c|}{$1 \mathrm{~mm}^{2}$} & \multicolumn{4}{|c|}{$2 \mathrm{~mm}^{2}$} & \multicolumn{4}{|c|}{$4 \mathrm{~mm}^{2}$} \\
\hline & \multicolumn{4}{|c|}{ Dilution } & \multicolumn{4}{|c|}{ Dilution } & \multicolumn{4}{|c|}{ Dilution } \\
\hline & $10^{\circ}$ & $10^{1}$ & $10^{2}$ & $10^{3}$ & $10^{\circ}$ & $10^{1}$ & $10^{2}$ & $10^{3}$ & $10^{\circ}$ & $10^{1}$ & $10^{2}$ & $10^{3}$ \\
\hline 1 section & $\mathrm{P}$ & IP & IP & IP & $\mathrm{P}$ & $\mathrm{P}$ & IP & IP & $\mathrm{P}$ & $\mathrm{P}$ & IP & IP \\
\hline 2 sections & $\mathrm{P}$ & IP & IP & IP & $\mathrm{P}$ & $\mathrm{P}$ & IP & IP & $\mathrm{P}$ & $\mathrm{P}$ & IP & IP \\
\hline 3 sections & $\mathrm{P}$ & IP & IP & IP & $\mathrm{P}$ & $\mathrm{P}$ & IP & IP & $\mathrm{P}$ & $\mathrm{P}$ & IP & IP \\
\hline 4 sections & $\mathrm{P}$ & $P$ & IP & IP & $\mathrm{P}$ & $\mathrm{P}$ & IP & IP & $\mathrm{P}$ & $\mathrm{P}$ & $\mathrm{P}$ & IP \\
\hline 5 sections & $\mathrm{P}$ & $\mathrm{P}$ & IP & IP & $\mathrm{P}$ & $\mathrm{P}$ & IP & IP & $\mathrm{P}$ & $\mathrm{P}$ & $\mathrm{P}$ & IP \\
\hline
\end{tabular}

IP, incomplete polyclonal pattern; $\mathrm{P}$, polyclonal pattern.

Table 2 Complementarity determining region 3 (CDR3) PCR results on reactive tissues

\begin{tabular}{|c|c|c|c|c|c|c|c|c|c|c|}
\hline & \multicolumn{5}{|c|}{ Paraffin wax embedded PCR results } & \multicolumn{5}{|c|}{ Fresh/frozen PCR results } \\
\hline & $n$ & $M$ & $I P$ & $P$ & $N S$ & $n$ & $M$ & $I P$ & $P$ & NS \\
\hline Reactive lymph node & 19 & 0 & 0 & 18 & 1 & 19 & 1 & 0 & 18 & 0 \\
\hline Tonsil & 4 & 0 & 0 & 4 & 0 & 4 & 0 & 0 & 4 & 0 \\
\hline biopsy with gastritis & 21 & 0 & 0 & 21 & 0 & ND & ND & ND & ND & ND \\
\hline PBL & ND & ND & ND & ND & ND & 4 & 0 & 0 & 4 & 0 \\
\hline
\end{tabular}

IP, incomplete polyclonal pattern; M, monoclonal pattern; PBL, peripheral blood lymphocytes; $n$, number of cases; ND, not done; NS, no signal; P, polyclonal pattern.

yielded four of the five electrophoresis patterns (M, P, IP, and NS) seen after PCR performed on frozen samples. No oligoclonal patterns were seen. PCR on DNA from frozen samples and paraffin wax embedded tissue of the same cases resulted in corresponding results (fig 1). Paraffin wax embedded tissue fixed in formol sublimate remained unsuitable for CDR3 PCR.

PCR ON REACTIVE TISSUES AND LYMPHOMAS PCR on DNA samples from peripheral blood lymphocyte fractions resulted in all cases in a polyclonal ladder of bands after electrophoresis and subsequent autoradiography (table 2). PCR on DNA isolated from both frozen and paraffin wax embedded tissue samples of all four tonsils, all 21 gastritis samples, and 18 of 19 reactive lymph nodes gave polyclonal patterns. A reactive lymph node from an individual with a chronic EBV infection revealed a strong band superimposed on a polyclonal ladder after PCR on frozen tissue DNA. PCR on paraffin wax embedded tissue from this patient was unsuccessful (table 2).

PCR on frozen tissue samples resulted in monoclonal patterns in eight of the nine $(89 \%)$ CLL and all eight (100\%) MCL samples. When DNA extracted from paraffin wax embedded tissue was used as the PCR template, the frequency of monoclonality was comparable: seven of nine $(78 \%)$ in CLL and seven of eight $(88 \%)$ in MCL (table 3). Three cases of CLL and one case of MCL from which paraffin wax embedded tissues were fixed in formol sublimate showed no signal (these cases are not mentioned in table 3). Monoclonality in MALT lymphomas was seen in 19 of 22 (86\%) frozen samples and in 21 of $35(60 \%)$ paraffin wax embedded samples. Paraffin wax embedded tissue was available for nine of the 19 frozen MALT lymphomas showing monoclonality. Three of these nine cases were monoclonal, whereas four were incomplete polyclonal and two showed no signal when paraffin wax embedded tissue was used as the PCR template. PCR on FL resulted in monoclonal patterns in six of $10(60 \%)$ frozen specimens, and four of $10(40 \%)$ paraffin wax embedded tissues (table 3). Monoclonal bands in FL were often superimposed on a polyclonal background.

In all cases of CLL, MCL, and FL and in 12 MALT lymphomas on which Southern blotting was performed, the number of rearranged bands detected by Southern blot analysis and hybridisation with the $\mathrm{JH}$ probe were compared with bands found after PCR. The principal difference between the two methods was that incomplete DJ rearrangements, as well as chromosomal breaks involving the $\mathrm{IgH}$ complex, such as $t(14 ; 18)$ and $t(11 ; 14)$, were detected by Southern blot analysis but not by PCR, because an intact VDJ complex is required for amplification. Although several tumours had more than one rearranged band after Southern blot analysis, in cases with monoclonal PCR patterns a single rearranged band was always seen.

\section{Discussion}

CDR3 PCR for the detection of clonality of lymphoproliferative lesions in tissue samples is becoming an important tool in surgical pathology. To analyse the value and limitations of this technique we applied a high resolution CDR3 PCR assay to frozen and paraffin wax embedded tissue samples from a large series of various types of lymphoproliferative disorders and polyclonal B cells. The results show that although the method is feasible, care has to be taken with the interpretation of the results, especially when small paraffin wax embedded samples are used. In general, the results of the PCR method directed at the FR3 region of the $\mathrm{IgH}$ gene were reproducible in both frozen and paraffin wax embedded tissues. The interpretation of test results was unambiguous because of the use of $6 \%$ denaturing polyacrylamide gels. Combining this method with radioactively labelled PCR products resulted in good

Table 3 Complementarity determining region 3 (CDR3) PCR results on B cell non-Hodgkin's lymphoma

\begin{tabular}{|c|c|c|c|c|c|c|c|c|c|c|c|c|}
\hline & \multicolumn{6}{|c|}{ Paraffin wax embedded PCR results } & \multicolumn{6}{|c|}{ Fresh/frozen PCR results } \\
\hline & $n$ & $M$ & $I P$ & $P$ & NS & $\%$ Positive & $n$ & $M$ & $I P$ & $P$ & NS & $\%$ Positive \\
\hline CLL & 9 & 7 & 0 & 0 & 2 & $78 \%$ & 9 & 8 & 0 & 0 & 1 & $89 \%$ \\
\hline MCL & 8 & 7 & 0 & 0 & 1 & $88 \%$ & 8 & 8 & 0 & 0 & 0 & $100 \%$ \\
\hline MALT & 35 & 21 & 10 & 1 & 3 & $60 \%$ & 22 & 19 & 2 & 1 & 0 & $86 \%$ \\
\hline FCBCC & 10 & 4 & 0 & 5 & 1 & $40 \%$ & 10 & 6 & 1 & 3 & 0 & $60 \%$ \\
\hline
\end{tabular}

CLL, chronic lymphocytic leukaemia; FCBCC, follicular centroblastic/centrocytic lymphoma; IP, incomplete polyclonal pattern; M, monoclonal pattern; MALT, mucosa associated lymphoid tissue lymphoma; MCL, mantle cell lymphoma; $n$, number of cases; NS, no signal; $\mathrm{P}$, polyclonal pattern. 
separation and visualisation of the PCR products. Meanwhile, a comparable method for analysing fluorescently labelled CDR3 PCR products with an automated sequencer is used successfully in our laboratory. ${ }^{11}$ We feel that both strategies have the advantage over the use of agarose gels stained with ethidium bromide, on which the difference between monoclonal and polyclonal patterns can be more arbitrary. ${ }^{16} 17$

By serially diluting DNA isolated from both frozen and paraffin wax embedded normal tonsillar tissue and subsequent PCR on all diluted samples, we showed that incomplete polyclonal or even pseudomonoclonal patterns could be induced by rigorous dilution. Similar findings were shown by Zhou and colleagues ${ }^{18}$ and by Wan et al. ${ }^{19}$ Our experiments showed that the minimum amount of tonsil derived DNA required for a complete polyclonal pattern is approximately $20 \mathrm{ng}$, which is comparable with the data from Wan et al on peripheral blood lymphocytes. ${ }^{19}$ Because tonsils contain as much as $60-95 \%$ B cells, this minimum amount of DNA is derived from approximately $6-9.5 \times 10^{3} \mathrm{~B}$ cells. For the investigation of small paraffin wax embedded biopsies, obtaining the required amount of template DNA can be difficult. The relatively simple, but crude, method for DNA isolation from paraffin wax embedded tissues necessitates a serial dilution of template DNA to find the adequate concentration of the template and to circumvent factors that inhibit the PCR. ${ }^{20}$ However, incomplete polyclonal patterns were already apparent in the 10 fold diluted samples when very small biopsies from a reactive tonsil were analysed (table 1). Of note, tonsils generally contain a much higher proportion of $B$ cells than other reactive tissues, and therefore the issue of obtaining a sufficient amount of template will be even more important in other reactive tissues. Furthermore, we realise that the cellular make up of a reactive tonsil differs from that of normal lymph nodes, gastric MALT, and other lymphoproliferative tissue. For instance, tonsils contain relatively large numbers of germinal centre derived B cells and the kinetics and results of CDR3 PCR on normal tonsillar DNA might be different from those obtained using tissue from other sites. From the above we conclude that, to avoid false diagnosis of a clonal population, duplicate analyses should be the standard procedure for each clonality PCR performed on any tissue. Because it is impossible to estimate the amount of amplifiable DNA recovered from paraffin wax embedded tissue or to foresee the PCR results of the DNA, we recommend the use of at least three serial dilutions. A population should be regarded as clonal only if the same clone appears at least twice.

The specificity of this PCR, as tested on a variety of reactive tissues, was $96 \%$ and $100 \%$ for frozen and paraffin wax embedded tissues, respectively. In only one lymph node was an indication of monoclonality found. However, this lymph node was obtained from an individual with a chronic EBV infection. It is possible that because of the infection in this patient, a small, probably non-malignant EBV infected clone was present. This case illustrates that any CDR3 PCR result should be interpreted in the context of other clinicopathological findings.

The observed sensitivity of PCR in lymphomas in our study differs between the various non-Hodgkin's lymphoma types. In MCL and CLL, a high sensitivity was seen in both frozen and paraffin wax embedded tissue. In FL, however, evidence for clonality was found less often. PCR on frozen samples from these lymphomas resulted in clonal patterns in $60 \%$, whereas PCR on paraffin wax embedded tissue from the same tumours showed clonal rearrangement in even lower percentages (table 3 ). For MALT lymphomas, good results were obtained using frozen tissue (86\% monoclonality), whereas in paraffin wax embedded tissue monoclonality could be detected in only $60 \%$. Several other studies have suggested possible explanations for the observed difference in PCR sensitivity between various types of non-Hodgkin's lymphoma. ${ }^{21-24}$ These include differences in mutation rates in the $\mathrm{IgH}$ locus (which are particularly high in FL, MALT lymphoma, and possibly a subgroup of CLL, ${ }^{25}$ and relatively low in MCL), leading to differences in the binding efficiency of the primers (especially the FR primer) to their target sequences. ${ }^{912426}$ Other mechanisms interfering with the detection of a clonal population with IgH PCR are inefficient recognition by the consensus primer of certain $\mathrm{VH}$ or $\mathrm{JH}$ families, ${ }^{24} 27$ incorrect or incomplete IgH gene rearrangements, ${ }^{27}{ }^{28}$ chromosomal translocations to the IgH locus (for example, BCL-2, BCL-6) rendering one allele unsuitable for VDJ amplification, ${ }^{27}$ and (especially in FL) the presence of abundant polyclonal B cells, which might mask the monoclonal population.

Determination of the difference between reactive and neoplastic lesions using histological criteria is extremely difficult in some cases of FL, and in these cases clonality analysis by IgH PCR would be most useful. However, the relatively low sensitivity of CDR3 PCR in these tumours reduces the diagnostic value of the PCR for this type of non-Hodgkin's lymphoma. PCR performed with additional primers might increase the detection sensitivity. Studies on various B cell non-Hodgkin's lymphomas show that using a FR1 primer set and/or FR2 primers as well as FR3 primers can increase sensitivity. ${ }^{91121242930}$ However, this makes the PCR analysis more complex and (because of the increasing number of primers and PCR product size) probably not suitable for routine use on paraffin wax embedded tissue. ${ }^{922} 24$ In addition, a BCL-2/JH PCR followed by gel hybridisation for the detection of the translocation $\mathrm{t}(14 ; 18)$ could be performed. $^{31}$ This assay might enhance the detection of malignant $\mathrm{B}$ cell populations in FL and some cases of diffuse large B cell lymphoma. Derksen et al, Segal et al, and McCarthy et al reported such enhancement of sensitivity $(1 \%, 7 \%$, and $10 \%$, respectively). ${ }^{61127}$ 
In our study, we investigated a series of gastritis and gastric MALT lymphoma specimens ( $n=21$ and $n=45$, respectively). We detected B cell monoclonality in $86 \%$ (frozen tissue) and $60 \%$ (paraffin wax embedded tissue) of lymphoma specimens, but monoclonality was not seen in our gastritis cases. This contrasts with most other studies, which have reported monoclonality in gastritis in up to $85 \%$ of cases. ${ }^{32-39}$ However, the reported incidences vary greatly and have been shown to occur in as few as $1-2 \%$ of cases. ${ }^{40}{ }^{41}$ No monoclonality was found in gastritis by Algara and colleagues ${ }^{42}$ and Sukpanichnant et al, ${ }^{13}$ which is in accord with our own findings. We cannot explain the variation, but some aspects that might be important are our rigid scoring criteria for monoclonality, variations in methodology or histological definition, and case selection bias. Various data indicate that the latter might be the key factor. High incidences of monoclonality were often found in and correlated with cases showing lymphoepithelial lesions $^{33}$ or lesions of suspect histology ${ }^{32}$ (according to the scoring system of Wotherspoon and colleagues ${ }^{43}$ ). Nakamura et al found that, in their group of patients with high frequencies of monoclonality, more patients progressed to malignant transformation compared with the group with low monoclonality frequencies. ${ }^{37}$ Similarly, Calvert and colleagues $^{34}$ showed a threefold increase in monoclonality in gastritis samples taken from resections elsewhere harbouring a monoclonal MALT lymphoma, compared with samples only showing active Helicobacter pylori associated chronic gastritis. Likewise, in the study by Rudolph et $a l^{36}{ }^{36}$ complete regression of dense lymphoid infiltrates after $H$ pylori eradication treatment took longer in patients with monoclonality than in those with polyclonal gastritis. Unfortunately, we do not have such data on our gastritis cases, but we believe that the aforementioned data demonstrate the influence of sampling on the detection of a monoclonal population in gastritis specimens. Of note, monoclonality incidences were not affected by variables, such as the presence or absence of $H$ pylori in the stomach ${ }^{32}$ and tissue type; both low and high incidences were reported in paraffin wax embedded specimens, ${ }^{3540}$ as well as in fresh frozen samples. ${ }^{32} 42$

We conclude that our CDR3 PCR is a useful assay for the distinction between reactive and neoplastic populations when performed under strict conditions and using a high resolution read out system.

This work was supported in part by grant KWF/NKB 96-1332 from the Dutch Cancer Society.

1 van Dongen JJ, Wolvers-Tettero IL. Analysis of immunoglobulin and T cell receptor genes. Part I: basic and technical aspects. Clin Chim Acta 1991;198:1-91.

2 Yamada M, Hudson S, Tournay O, et al. Detection of minimal disease in hematopoietic malignancies of the B-cell lineage by using third-complementarity-determining region (CDR-III)-specific probes. Proc Natl Acad Sci U S A 1989; 86:5123-7.

3 Trainor KJ, Brisco MJ, Story CJ, et al. Monoclonality in B-lymphoproliferative disorders detected at the DNA level. Blood 1990;75:2220-2.

4 Arnold A, Cossman J, Bakhshi A, et al. Immunoglobulingene rearrangements as unique clonal markers in human lymphoid neoplasms. N Engl f Med 1983;309:1593-9.
5 Wan JH, Trainor KJ, Brisco MJ, et al. Monoclonality in B cell lymphoma detected in paraffin wax embedded sections using the polymerase chain reaction. $\mathcal{F}$ Clin Pathol 1990;43: $888-90$.

6 McCarthy KP, Sloane JP, Wiedemann LM. Rapid method for distinguishing clonal from polyclonal B cell populations in surgical biopsy specimens. F Clin Pathol 1990;43:429-32.

7 Inghirami G, Szabolcs MJ, Yee HT, et al. Detection of immunoglobulin gene rearrangement of B cell nonHodgkin's lymphomas and leukemias in fresh, unfixed and formalin-fixed, paraffin-embedded tissue by polymerase chain reaction. Lab Invest 1993;68:746-57.

8 Kuppers R, Zhao M, Rajewsky K, et al. Detection of clonal $\mathrm{B}$ cell populations in paraffin-embedded tissues by
polymerase chain reaction. Am $\mathcal{F}$ Pathol 1993;143:230-9.

9 Segal GH, Jorgensen T, Masih AS, et al. Optimal primer selection for clonality assessment by polymerase chain reaction analysis: I. Low grade B-cell lymphoproliferative disorders of nonfollicular center cell type [see comments]. Hum Pathol 1994;25:1269-75.

10 Owen RG, Johnson RJ, Rawstron AC, et al. Assessment of IgH PCR strategies in multiple myeloma. 7 Clin Pathol 1996;49:672-5.

11 Derksen PWB, Langerak AW, Kerkhof E, et al. Comparison of different PCR based approaches for clonality assessment of immunoglobulin heavy chain gene rearrangements in B cell neoplasia. Mod Pathol 1999;12:749-805

12 Pan LX, Diss TC, Peng HZ, et al. Clonality analysis of defined B-cell populations in archival tissue sections using microdissection and the polymerase chain reaction. Histopathology 1994;24:323-7.

13 Sukpanichnant S, Vnencak-Jones CL, McCurley TL. Determination of B-cell clonality in paraffin-embedded endoscopic biopsy specimens of abnormal lymphocytic infiltrates and gastrointestinal lymphoma by polymerase chain reaction [see comments]. Am f Clin Pathol 1994;102: 299-305.

14 Aiello A, Giardini R, Tondini C, et al. PCR-based clonality analysis: a reliable method for the diagnosis and follow-up monitoring of conservatively treated gastric B-cell MALT lymphomas? Histopathology 1999;34:326-30.

15 Brisco MJ, Tan LW, Orsborn AM, et al. Development of a highly sensitive assay, based on the polymerase chain reaction, for rare B-lymphocyte clones in a polyclonal population. Br f Haematol 1990;75:163-7.

16 Reed TJ, Reid A, Wallberg K, et al. Determination of B-cell clonality in paraffin-embedded lymph nodes using the polymerase chain reaction. Diagn Mol Pathol 1993;2:42-9.

17 Sioutos N, Bagg A, Michaud GY, et al. Polymerase chain reaction versus Southern blot hybridization. Detection of immunoglobulin heavy-chain gene rearrangements. Diagn Mol Pathol 1995;4:8-13.

18 Zhou XG, Sandvej K, Gregersen N, et al. Detection of clonal B cells in microdissected reactive lymphoproliferations: possible diagnostic pitfalls in PCR analysis of immunoglobulin heavy chain gene rearrangement. Mol Pathol 1999;52:104-10.

19 Wan JH, Sykes PJ, Orell SR, et al. Rapid method for detecting monoclonality in B cell lymphoma in lymph node aspirates using the polymerase chain reaction [published erratum appears in $\mathcal{F}$ Clin Pathol 1992;45:1124]. F Clin Pathol 1992;45:420-3.

20 Karlsen F, Kalantari M, Chitemerere M, et al. Modifications of human and viral deoxyribonucleic acid by formaldehyde fixation. Lab Invest 1994;71:604-11.

21 Deane M, McCarthy KP, Wiedemann LM, et al. An improved method for detection of B-lymphoid clonality by polymerase chain reaction. Leukemia 1991;5:726-30

22 Diss TC, Peng H, Wotherspoon AC, et al. Detection of monoclonality in low-grade B-cell lymphomas using the polymerase chain reaction is dependent on primer selection and lymphoma type. F Pathol 1993;169:291-5.

23 Inagaki $\mathrm{H}$, Nonaka $M$, Nagaya $\mathrm{S}$, et al. Monoclonality in gastric lymphoma detected in formalin-fixed, paraffinembedded endoscopic biopsy specimens using immunohistochemistry, in situ hybridization, and polymerase chain reaction. Diagn Mol Pathol 1995;4:32-8.

24 Aubin J, Davi F, Nguyen Salomon F, et al. Description of a novel FR1 IgH PCR strategy and its comparison with three other strategies for the detection of clonality in B cell malignancies. Leukemia 1995;9:471-9.

25 Oscier DG, Thompsett A, Zhu D, et al. Differential rates of somatic hypermutation in $\mathrm{V}(\mathrm{H})$ genes among subsets of chronic lymphocytic leukemia defined by chromosomal chronic lymphocytic leukemia defined

26 Levy R, Levy S, Cleary ML, et al. Somatic mutation in Levy R, Levy S, Cleary ML, et al. Somatic mutation
human B-cell tumors. Immunol Rev 1987;96:43-58.

27 Segal GH, Wittwer CT, Fishleder AJ, et al. Identification of monoclonal B-cell populations by rapid cycle polymerase chain reaction. A practical screening method for the detection of immunoglobulin gene rearrangements. Am F Pathol 1992;141:1291-7

28 Trainor KJ, Brisco MJ, Wan JH, et al. Gene rearrangement in B- and T-lymphoproliferative disease detected by the polymerase chain reaction. Blood 1991;78:192-6.

29 Hayashi Y, Fukayama M, Funata N, et al. Polymerase chain reaction screening of immunoglobulin heavy chain and $\mathrm{T}$ cell receptor gamma gene rearrangements: a practical approach to molecular DNA analysis of non-Hodgkin's lymphoma in a surgical pathology laboratory. Pathol Int 1999;49:110-17.

30 Fodinger M, Winkler K, Mannhalter C, et al. Combined polymerase chain reaction approach for clonality detection in lymphoid neoplasms. Diagn Mol Pathol 1999;8:80-91. 
31 Corbally N, Grogan L, Dervan PA, et al. The detection of specific gene rearrangements in non-Hodgkin's lymphoma using the polymerase chain reaction. Br f Cancer 1992;66: $805-9$.

32 Sorrentino D, Ferraccioli GF, DeVita S, et al. B-cell clonality and infection with Helicobacter pylori: implications fo development of gastric lymphoma. Gut 1996;38:837-40.

33 Hsi ED, Greenson JK, Singleton TP, et al. Detection of immunoglobulin heavy chain gene rearrangement by polymerase chain reaction in chronic active gastritis associated with Helicobacter pylori. Hum Pathol 1996;27:290-6.

34 Calvert RJ, Evans PA, Randerson JA, et al. The significance of B-cell clonality in gastric lymphoid infiltrates. F Pathol 1996;180:26-32.

35 Torlakovic E, Cherwitz DL, Jessurun J, et al. B-cell gene rearrangement in benign and malignant lymphoid proliferations of mucosa-associated lymphoid tissue and lymph nodes. Hum Pathol 1997;28:166-73.

36 Rudolph B, Bayerdorffer E, Ritter M, et al. Is the polymerase chain reaction or cure of Helicobacter pylori infection of help in the differential diagnosis of early gastric mucosaassociated lymphatic tissue lymphoma? f Clin Oncol 1997; associated lym

37 Nakamura S, Aoyagi K, Furuse M, et al. B-cell monoclonality precedes the development of gastric MALT lymphoma in Helicobacter pylori-associated chronic gastritis. Am $\mathcal{F}$ Pathol 1998;152:1271-9.
38 El Zimaity HM, El Zaatari FA, Dore MP, et al. The differential diagnosis of early gastric mucosa-associated ymphoma: polymerase chain reaction and paraffin section immunophenotyping. Mod Pathol 1999;12:885-93.

39 Saxena A, Moshynska O, Kanthan R, et al. Distinct B-cell clonal bands in Helicobacter pylori gastritis with lymphoid chyperplasia [in process citation]. F Pathol 2000;190:4754

40 Savio A, Franzin G, Wotherspoon AC, et al. Diagnosis and posttreatment follow-up of Helicobacter pylori-positive gastric lymphoma of mucosa-associated lymphoid tissue: histology, polymerase chain reaction, or both? Blood 1996; 87:1255-60.

41 de Mascarel A, Dubus P, Belleannee G, et al. Low prevalence of monoclonal B cells in Helicobacter pylori gastritis patients with duodenal ulcer [see comments]. Hum Pathol 1998;29:784-90.

42 Algara P, Martinez P, Sanchez L, et al. The detection of B-cell monoclonal populations by polymerase chain reaction: accuracy of approach and application in gastric endoscopic biopsy specimens. Hum Pathol 1993;24:1184-8.

43 Wotherspoon AC, Doglioni C, Diss TC, et al. Regression of primary low-grade B-cell gastric lymphoma of mucosaassociated lymphoid tissue type after eradication of Helicobacter pylori [see comments]. Lancet 1993;342:575-7. 